\title{
Disrupted Dentate Granule Cell Chloride Regulation Enhances Synaptic Excitability during Development of Temporal Lobe Epilepsy
}

\author{
Hemal R. Pathak, ${ }^{1}$ Florian Weissinger, ${ }^{4}$ Miho Terunuma, ${ }^{1}$ Gregory C. Carlson, ${ }^{3}$ Fu-Chun Hsu, ${ }^{4}$ Stephen J. Moss, ${ }^{1}$ and \\ Douglas A. Coulter ${ }^{1,2,4}$ \\ Departments of ${ }^{1}$ Neuroscience, ${ }^{2}$ Pediatrics, and ${ }^{3}$ Psychiatry, University of Pennsylvania School of Medicine, Philadelphia, Pennsylvania 19104, and \\ ${ }^{4}$ Pediatric Regional Epilepsy Program and Joseph Stokes Research Institute of the Children's Hospital of Philadelphia, Philadelphia, Pennsylvania 19104
}

\begin{abstract}
$\mathrm{GABA}_{\mathrm{A}}$ receptor-mediated inhibition depends on the maintenance of intracellular $\mathrm{Cl}^{-}$concentration $\left(\left[\mathrm{Cl}^{-}\right]_{\text {in }}\right)$ at low levels. In neurons in the developing $\mathrm{CNS},\left[\mathrm{Cl}^{-}\right]_{\text {in }}$ is elevated, $E_{\mathrm{GABA}}$ is depolarizing, and GABA consequently is excitatory. Depolarizing GABAergic synaptic responses may be recapitulated in various neuropathological conditions, including epilepsy. In the present study, rat hippocampal dentate granule cells were recorded using gramicidin perforated patch techniques at varying times (1-60 d) after an epileptogenic injury, pilocarpine-induced status epilepticus (STEP). In normal, non-epileptic animals, these strongly inhibited dentate granule cells act as a gate, regulating hippocampal excitation, controlling seizure initiation and/or propagation. For 2 weeks after STEP, we found that $E_{\text {GABA }}$ was positively shifted in granule cells. This shift in $E_{\mathrm{GABA}}$ altered synaptic integration, increased granule cell excitability, and resulted in compromised "gate" function of the dentate gyrus. $E_{\mathrm{GABA}}$ recovered to control values at longer latencies post-STEP (2-8 weeks), when animals had developed epilepsy. During this period of shifted $E_{\mathrm{GABA}}$, expression of the $\mathrm{Cl}^{-}$extruding $\mathrm{K}^{+} / \mathrm{Cl}^{-}$cotransporter, $\mathrm{KCC} 2$ was decreased. Application of the KCC2 blocker, furosemide, to control neurons mimicked $E_{\mathrm{GABA}}$ shifts evident in granule cells post-STEP. Furthermore, post-STEP and furosemide effects interacted occlusively, both on $E_{\mathrm{GABA}}$ in granule cells, and on gatekeeper function of the dentate gyrus. This suggests a shared mechanism, reduced KCC2 function. These findings demonstrate that decreased expression of KCC2 persists for weeks after an epileptogenic injury, reducing inhibitory efficacy and enhancing dentate granule cell excitability. This pathophysiological process may constitute a significant mechanism linking injury to the subsequent development of epilepsy.
\end{abstract}

Key words: temporal lobe epilepsy; dentate gyrus; inhibition; chloride; $\mathrm{GABA}_{\mathrm{A}}$ receptor; hippocampus

\section{Introduction}

Temporal lobe epilepsy (TLE) is an acquired condition initiated by injury to the CNS. In animal models of TLE, the precipitating insult can be status epilepticus (STEP), induced by administration of convulsants, such as pilocarpine. In the pilocarpine TLE model, STEP is initiated, resolves, and then is followed by a characteristic seizure-free period. This 1-4 week latent period ends with the subsequent emergence of spontaneous recurrent seizures which define epilepsy (Cavalheiro et al., 1991; Mello et al., 1993). A latent period also exists in human epilepsy, spanning months or years (Annegers et al., 1980; Salazar et al., 1985; Weiss et al., 1986). The synaptic changes during the latent period, especially with regards to inhibition, continue to be studied because they are likely fundamentally important to the development of chronic epilepsy.

\footnotetext{
Received April 20, 2007; revised 0ct. 25, 2007; accepted 0ct. 26, 2007.

This work was supported by National Institutes of Health (NIH) Grants R37 NS-32403 and R01 NS-38572 (D.A.C.) and a Graduate Training in Systems and Integrative Biology Grant NIH GM 07517 (H.R.P.).

Correspondence should be addressed to Dr. Douglas A. Coulter, Children's Hospital of Philadelphia, Abramson Pediatric Research Center, Room 410, 3516 Civic Center Boulevard, Philadelphia, PA 19104-4318. E-mail: coulterd@email.chop.edu.

DOI:10.1523/JNEUROSCI.4390-07.2007

Copyright $\odot 2007$ Society for Neuroscience $\quad$ 0270-6474/07/2714012-11\$15.00/0
}

Compromised inhibition of dentate granule cells has been hypothesized to generate limbic circuitry conducive to initiation and/or propagation of seizures (Heinemann et al., 1992; Lothman et al., 1992; Behr et al., 1998). In adult brain, dentate granule cells are strongly inhibited by multiple interneuron variants (Halasy and Somogyi, 1993; Han et al., 1993). This endows the dentate gyrus with the properties of a tightly regulated filter, limiting throughput between the entorhinal cortex and the hippocampus (Collins et al., 1983; Heinemann et al., 1992; Lothman et al., 1992). Although this is true in the dentate gyrus of adult animals, in immature dentate granule cells, $E_{\mathrm{GABA}}$ is more depolarized (Ben-Ari et al., 1989; Owens et al., 1996; Hollrigel et al., 1998; Dzhala and Staley, 2003). Shifts in $E_{\mathrm{GABA}}$ during postnatal maturation are mediated by increased expression of the neuron specific $\mathrm{K}^{+} \mathrm{Cl}^{-}$cotransporter, $\mathrm{KCC} 2$, which extrudes $\mathrm{Cl}^{-}$, setting a more hyperpolarized $\mathrm{Cl}^{-}$equilibrium (Payne et al., 1996; Rivera et al., 1999; Lee et al., 2005).

GABA acts as an inhibitory neurotransmitter only when $E_{\mathrm{GABA}}$ is sufficiently negative to impede action potential initiation. In the adult brain, robust KCC2 expression is necessary to maintain $E_{\mathrm{GABA}}$ in a range that allows GABA to act as an inhibitory neurotransmitter. KCC2 downregulation accompanied by a depolarized $E_{\mathrm{GABA}}$ has been seen in several in vivo and in vitro 
injury models (van den Pol et al., 1996; Nabekura et al., 2002; Rivera et al., 2002, 2004; Khalilov et al., 2003; Toyoda et al., 2003; Jin et al., 2005; Bonislawski et al., 2007). An injury-induced reversion to a depolarized $E_{\mathrm{GABA}}$ in dentate granule cells would substantially alter the circuit properties of the dentate gyrus, and potentially contribute to seizure initiation in the limbic system.

In the present study, we demonstrate that there is a positive shift in dentate granule cell $E_{\mathrm{GABA}}$ after STEP in the pilocarpine rat model of TLE. This $E_{\mathrm{GABA}}$ shift is temporally restricted to the latent period, and is not seen in epileptic animals, months postSTEP. Granule cell $E_{\mathrm{GABA}}$ post-STEP is particularly sensitive to activity-dependent increases in $\mathrm{Cl}^{-}$influx, reflecting decreased $\mathrm{Cl}^{-}$extrusion capacity. This positively shifted $E_{\mathrm{GABA}}$ is sufficient to alter synaptic integration in dentate granule cells, facilitating action potential firing.

\section{Materials and Methods}

Pilocarpine-induced epilepsy. The protocol for pilocarpine injection was similar to that previously reported (Mello et al., 1993; Gibbs et al., 1997; Ang et al., 2006). Adult male Sprague Dawley rats (235-265 g) were pretreated with scopolamine methyl nitrate (1 mg/kg, subcutaneous) 30 min. before pilocarpine injection. Status Epilepticus (STEP) was induced by injection of pilocarpine $(405 \mathrm{mg} / \mathrm{kg}$, s.c.). After $1 \mathrm{~h}$ of continuous seizures, diazepam $(7.5 \mathrm{mg} / \mathrm{kg}$, s.c.) was administered to terminate STEP. Rats were hand fed after STEP until they were able to eat and drink on their own (3-4 d). To assess epilepsy development, animals were video monitored for seizures. Epileptic animals were classified as such after at least two observed spontaneous seizures. Before experiments, epileptic animals were monitored for $24 \mathrm{~h}$ to select rats without acute seizures. Chronically epileptic animals used in this study were killed 4-8 weeks after STEP. All experimental protocols were approved by the CHOP Institutional Animal Care and Use Committee. Age matched naive rats or rats given a subconvulsive dose of pilocarpine were used as controls. Data from both groups of control animals were pooled because there was no difference between groups.

Slice preparation. Animals were decapitated and brains were quickly placed in cold sucrose-aCSF (in mM: 120 Sucrose, $3.2 \mathrm{KCl}, 1.25$ HEPES, 2 $\mathrm{MgCl}_{2}, 2 \mathrm{CaCl}_{2}, 26 \mathrm{NaHCO}_{3}, 10$ glucose) for 2 min before slicing by vibratome (VT1000S; Leica, Deerfield, IL). After cutting (350 $\mu \mathrm{m}$ coronal sections), slices were allowed to recover in standard aCSF (sucrose replaced with $120 \mathrm{~mm} \mathrm{NaCl}$ ) at room temperature. Recordings were conducted at $34^{\circ} \mathrm{C}$. For most patch clamp studies, slices were cut coronally. For the voltage sensitive dye imaging studies (see below), hippocampal/entorhinal cortical (HEC) slices were cut at $12^{\circ}$ off horizontal from the ventral hippocampus at a thickness of $400 \mu \mathrm{m}$, as described previously (Rafiq et al., 1993; Ang et al., 2005, 2006).

Electrophysiology. For perforated patch recordings, 3-4 M $\Omega$ electrodes were fabricated using a P-97 micropipette puller (Sutter Instruments, Novato, CA). All electrodes were made from $1.5 \mathrm{~mm}$ borosilicate glass capillary tubes (World Precision Instruments, Sarasota, FL). Electrode tips were filled with gramicidin-free pipette solution $(150 \mathrm{~mm} \mathrm{KCl}, 10$ mM HEPES, pH 7.25) and back-filled with pipette solution containing gramicidin D $(50 \mu \mathrm{g} / \mathrm{ml})$. To isolate GABA currents, TTX (400 nM), 6, 7-dinitroquinoxaline-2 3dione (DNQX, $10 \mu \mathrm{M}$ ), and D-(-)-2-amino-5phosphonopentanoic acid (APV, $50 \mu \mathrm{M}$ ) (Tocris, Ellisville, MO) were added to the aCSF to block $\mathrm{Na}^{+}$channels, AMPA receptors, and NMDA receptors, respectively. For UV photolysis experiments, slices were incubated in continuously recirculated aCSF containing $\mathrm{O}$-(CNB-caged) GABA (1 mM) (Invitrogen, Carlsbad, CA). GABA was focally uncaged at the soma by a UV laser pulse, targeting the cell through the microscope objective (Enterprise II, Coherent Scientific, South Australia, Australia). For evoked responses, a bipolar tungsten electrode (World Precision Instruments) was placed within $100 \mu \mathrm{m}$ of the patch clamped cell to stimulate local interneurons, and TTX was omitted from the bathing solution. Signals were recorded with an Axopatch 200B amplifier (Molecular Devices, Sunnyvale, CA), filtered at $2 \mathrm{kHz}$ and digitized at $10 \mathrm{kHz}$. Only perforated patch recordings with access resistance $(\mathrm{Ra}) \leq 80 \mathrm{M} \Omega$ were accepted. Series resistance was monitored at $2 \mathrm{~min}$ intervals and data were rejected when resistance suddenly decreased, indicating rupture of the perforated patch. Data were analyzed with Clampfit (Molecular Devices) and SigmaStat software (Systat Software, Point Richmond, CA). $E_{\mathrm{GABA}}$ was determined by stepping $V_{\text {hold }}$ in $10 \mathrm{mV}$ increments and plotting an $I-V$ curve, or using $100 \mathrm{~ms}, 55 \mathrm{mV}$ ramps while applying GABA. Junction potential was $3.6 \mathrm{mV}$ and corrected off-line.

Western blotting. The dentate gyrus was dissected from rat hippocampal slices, and homogenized in a buffer containing $20 \mathrm{~mm}$ Tris- $\mathrm{HCl}, \mathrm{pH}$ 8.0, $150 \mathrm{~mm} \mathrm{NaCl}, 5 \mathrm{~mm}$ EDTA, $1 \%$ Triton X-100, 0.1\% SDS, $10 \mathrm{~mm} \mathrm{NaF}$, $2 \mathrm{~mm} \mathrm{Na}_{3} \mathrm{VO}_{4}, 10 \mathrm{~mm} \mathrm{Na}_{4} \mathrm{P}_{2} \mathrm{O}_{7}, 10 \mathrm{mg} / \mathrm{ml}$ leupeptin, $1 \mathrm{mg} / \mathrm{ml}$ aprotinin, $10 \mathrm{mg} / \mathrm{ml}$ antipain and $250 \mathrm{mg} / \mathrm{ml}$ 4-(2-Aminoethl)benzenesulfonyl fluoride hydrochloride. Insoluble material was removed by centrifugation. Lysate $(20 \mu \mathrm{g})$ was mixed with a sample buffer for SDS-PAGE, followed by electrophoresis and immunoblotting with an antibody specific to KCC2 (courtesy of Dr. John Payne, University of California, Davis) and visualized by ECL (Pierce, Rockford, IL). Blots were then quantified using the CCD based Fujifilm (Tokyo, Japan) LAS 3000 system.

Optical recordings using voltage-sensitive dyes. HEC slices were stained with the voltage sensitive dye (VSD) JPW $3031(0.125 \mathrm{mg} / \mathrm{ml}$, University of Connecticut Health Center) in ACSF for $10 \mathrm{~min}$, and imaged in an oxygenated interface chamber $\left(34 \pm 1^{\circ} \mathrm{C}\right)$ using an $80 \times 80 \mathrm{CCD}$ camera recording at a $1-2 \mathrm{kHz}$ frame rate (NeuroCCD; RedShirt Imaging, Decatur, GA). Epi-illumination was provided by a $150 \mathrm{~W}$ xenon lamp driven by a stable power supply (Opti-quip, Highland Mills, NY). The CCD chip well size $\left(215,000 \mathrm{e}^{-}\right)$requires use of low light intensities, which minimized photodynamic damage. A $4 \times$ objective lens $(0.28 \mathrm{NA}$; Olympus, Tokyo, Japan) imaged a $2.5 \times 2.5 \mathrm{~mm}$ region in the dentate gyrus and area CA 3 of the hippocampus $(32 \times 32 \mu \mathrm{m}$ region imaged per pixel). The intensity of the VSD signal and the amplitude of a simultaneously intracellularly recorded neuronal response during synaptic activation correlate linearly. In our previous studies, for 8 patch recording/ VSD experiments using JPW 3031, the slope of the linear correlation between VSD and patch recordings was $0.11 \pm 0.0055 \% \Delta \mathrm{F} / \mathrm{F} / 10 \mathrm{mV}$ (Ang et al., 2006).

Data analysis of optical recordings. All analysis was performed in IGOR (WaveMetrics, Lake Oswego, OR) on 12 trials averages. Data were displayed as the change in fluorescence divided by the resting fluorescence $(\Delta \mathrm{F} / \mathrm{F})$. To be consistent with electrophysiological conventions, depolarizing $\Delta \mathrm{F} / \mathrm{F}$ signals were displayed as positive signals (warmer colors) and hyperpolarizations represented as negative signals (colder colors).

Areal analysis. VSD recordings are spatiotemporal signals with four dimensions: space (X and Y), time, and voltage. To facilitate analysis of the filter function of the dentate gyrus, we conducted areal analysis of our VSD recordings, as previously described (Ang et al., 2006). This technique involves simplifying the voltage parameter of the data to a binary number, depolarized or not depolarized. This allows determination of the number of pixels in the dentate gyrus and area CA3a that exhibited significant depolarization after perforant path stimulation. The threshold value was set to be $>0.04 \% \Delta \mathrm{F} / \mathrm{F}$, corresponding to responses $\geq 3 \mathrm{SD}$ over noise levels. The activated pixel number was normalized against the total pixel number in each region of interest, generating a $\%$ area activated measure, and plotted against time. This "areal analysis" is optimal for measuring signals in CA3, which can be lost when averaging pixels over a large, sparsely activating region of interest, such as CA3 (cf. Ang et al., 2006).

Significance was assessed at $p \leq 0.05$ level. ANOVA was performed when appropriate. All results are reported as mean \pm SEM.

\section{Results}

Dentate granule cell $E_{\mathrm{GABA}}$ becomes more positive after STEP In the pilocarpine rat model of TLE, we began our studies using perforated patch recording techniques to measure $E_{\mathrm{GABA}}$ in dentate granule cells as it varied with time after STEP-induced injury to the brain. $\mathrm{GABA}_{\mathrm{A}}$ receptor-mediated currents were isolated pharmacologically. We found that $24 \mathrm{~h}$ after STEP, $E_{\mathrm{GABA}}$ was positively shifted relative to control (Fig. $1 B)(t$ test, $p<0.05$ ). We then assayed the reversal potential of GABAergic currents at 
multiple time points post-STEP to determine whether the depolarized $E_{\mathrm{GABA}}$ was a permanent change in dentate granule cell function. Median $E_{\mathrm{GABA}}$ and the distribution of $E_{\mathrm{GABA}}$ values among the treatment groups differed significantly (Fig. 1B) (rank-sum test). The $E_{\mathrm{GABA}}$ values at 1 week post-STEP were widely variable and were not normally distributed (Fig. $1 B$ ) (K-S test, $p<0.05$ ). Some cells appeared similar to controls whereas others exhibited more positive values for $E_{\mathrm{GABA}}$. These results demonstrated that a depolarized $E_{\mathrm{GABA}}$ persisted beyond the acute response to STEP in a subset of granule cells. Surprisingly, we found that $E_{\mathrm{GABA}}$ was no longer positively shifted 2 weeks after STEP. By the 2 week time point, the typical end of the latent period (Cavalheiro et al., 1991; Mello et al., 1993), $E_{\mathrm{GABA}}$ was similar to control ( $t$ test, $p>0.05$ ). Because $\mathrm{GABA}_{\mathrm{A}}$ receptors conduct both $\mathrm{Cl}^{-}$and $\mathrm{HCO}_{3}{ }^{-}$, we repeated the experiments at the 1 week time point in $\mathrm{HCO}_{3}{ }^{-}$free aCSF to isolate the $\mathrm{Cl}^{-}$component of the current. Under these conditions, cells still exhibited a positively shifted $E_{\mathrm{GABA}}(-52.7 \pm$ $2.2 \mathrm{mV}, n=3$ cells) relative to control. Because we focally uncaged GABA over the cell body, limiting the influence of dendritic GABA receptors, our results are most relevant to $\mathrm{Cl}^{-}$regulation in the cell body.

Next, we plotted histograms of $E_{\mathrm{GABA}}$ distributions at each time point (Fig. $1 C-F)$ to determine whether there were multiple subpopulations of cells. Clearly, 1 week after STEP, two peaks in the distribution were present (Fig. 1D). This result indicated the presence of a subgroup of cells in which $E_{\mathrm{GABA}}$ was similar to control and another subgroup in which $E_{\mathrm{GABA}}$ was depolarized relative to control.

\section{Synaptic activity reveals additional deficits in $\mathrm{Cl}^{-}$regulation in post-STEP granule cells}

Measuring $E_{\mathrm{GABA}}$ in resting neurons in slice preparations is an imperfect method to assess $\mathrm{Cl}^{-}$regulatory capacity. Even when $\mathrm{Cl}^{-}$ regulatory mechanisms are compromised, neurons could retain sufficient $\mathrm{Cl}^{-}$extrusion capability to maintain a hyperpolarized $E_{\mathrm{GABA}}$ under resting, inactive conditions. This diminished capacity could rapidly be overwhelmed by enhancing inhibitory synaptic activity (cf. Jin et al., 2005).

We were particularly interested in studying the two subpopulations of cells that are apparent 1 week after STEP. $E_{\mathrm{GABA}}$ in one subpopulation is more positive than in control dentate granule cells. $E_{\mathrm{GABA}}$ in the second subpopulation is similar to that in control dentate granule cells. We defined the subgroup of cells with $E_{\mathrm{GABA}}<-65 \mathrm{mV}$ at rest as the "apparently normal" subpopulation. The subgroup of cells with $E_{\mathrm{GABA}} \geq-65 \mathrm{mV}$ at rest was defined as the "overtly abnormal" population. During our initial experiments (Fig. 1), we observed that $E_{\mathrm{GABA}}$ in cells from the apparently normal group quickly became more positive after multiple applications of GABA, an effect that was not seen in
C

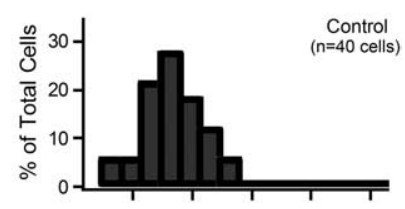

$\mathrm{D}$

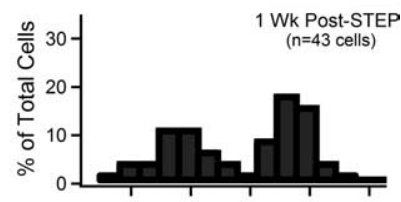

E

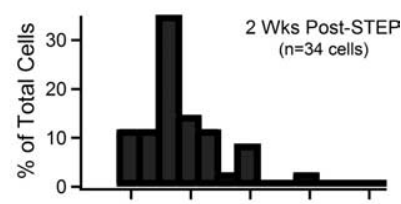

$\mathrm{F}$

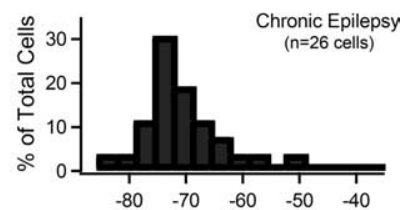

$\mathrm{E}_{\mathrm{GABA}}(\mathrm{mV})$

Figure 1. Dentate granule cell $E_{G A B A}$ shifts to more positive values after STEP. A, Sample traces from dentate granule cells depict the shift in $E_{\text {GABA }} 1$ week after $S T E P$. Each trace represents a response to $25 \mathrm{~ms}$ focal uncaging of GABA on the cell body at ferent holding potentials ( -75 to $-35 \mathrm{mV}$ in $10 \mathrm{mV}$ increments). Graph shows $I-V$ plots for the traces shown. $B$, Box-and$(n=43), 2$ weeks post-STEP $(n=34)$, and chronically epileptic $(n=26)$ animals. The plot shows the distribution and cells is not normally distributed. The distribution appears bimodal with one subpopulation similar to controls, with a mean $E_{G A B A}$ more negative than $-65 \mathrm{mV}$. A second group has a mean $E_{G A B A}$ more positive than $-65 \mathrm{mV}$. $\boldsymbol{E}$, By 2 weeks after STEP, the dentate granule cell $E_{\mathrm{GABA}}$ values return to a normal distribution with a hyperpolarized value similar to controls. $\boldsymbol{F}$, The $E_{\mathrm{GABA}}$ distribution and median value in chronically epileptic animals is similar to controls. Bin width in all histograms is $3.3 \mathrm{mV}$.

neurons from control animals (data not shown). This observation suggested that $\left[\mathrm{Cl}^{-}\right]_{\text {in }}$ was accumulating as a result of repeated GABA receptor activity. Despite the apparently normal resting $E_{\mathrm{GABA}}$ in these cells, they appeared to have a diminished ability to maintain $\mathrm{Cl}^{-}$homeostasis. Without the ability to rapidly extrude $\mathrm{Cl}^{-}$, repeated inhibitory synaptic activity would cause additional depolarization of $E_{\mathrm{GABA}}$ during periods of sustained activity, a time when inhibition is normally recruited to check excitation. Because GABA is the primary inhibitory neurotransmitter in this system, a failure of GABAergic inhibition would compromise normal circuit function. In two previous studies it was shown that $E_{\mathrm{GABA}}$ in KCC2 deficient cells recovers more slowly from a GABA induced $\mathrm{Cl}^{-}$load (Zhu et al., 2005), or recovers normally but shifts faster during periods of repeated IPSC activation (Jin et al., 2005). We therefore conducted a series of additional experiments to determine how post-STEP neurons respond to sustained periods of inhibitory synaptic activity.

To assess the ability of post-STEP dentate granule cells to extrude $\mathrm{Cl}^{-}$under dynamic, active conditions, we evoked IPSCs 1-12 times at a frequency of $0.2 \mathrm{~Hz}$, while holding the cell at a potential $30 \mathrm{mV}$ depolarized relative to resting $E_{\mathrm{GABA}}$ (Fig. 2), a 
1 wk Post-Step

$A_{i}$

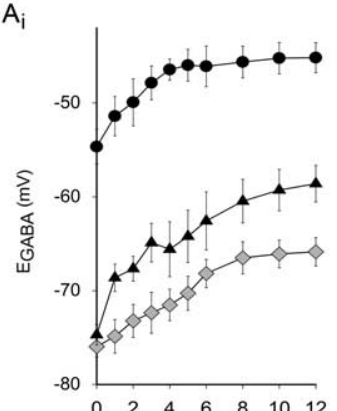

$\mathrm{A}_{\mathrm{ii}}$

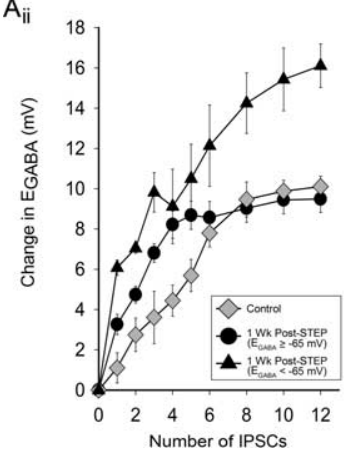

2 wks Post-Step

$B_{\mathrm{i}}$

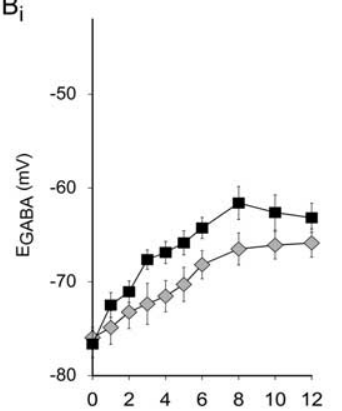

$\mathrm{B}_{\mathrm{ii}}$

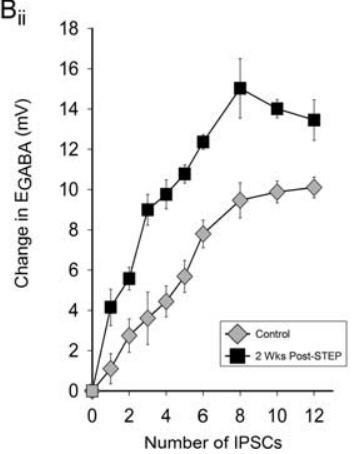

Chronic Epilepsy

$\mathrm{C}_{\mathrm{i}}$

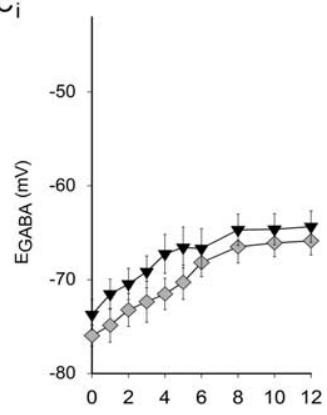

$\mathrm{C}_{\mathrm{ii}}$

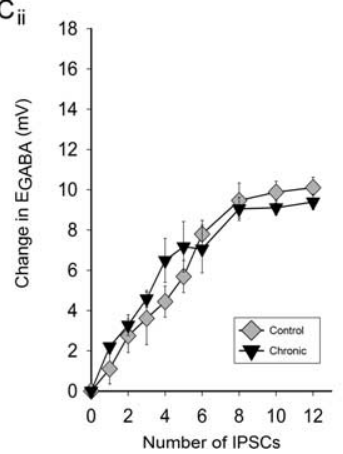

Figure 2. Dentate granule cells exhibit a decreased capacity to regulate intracellular $\mathrm{Cl}^{-}$concentration after multiple IPSCS 1 and 2 weeks after STEP, and this returns to control levels in chronic epilepsy. Ai, Positive shifts in $E_{\text {GABA }}$ values are shown after multiple IPSCs in granule cells from 1 week post-STEP animals. The data presented include overtly abnormal dentate granule cells $\left(E_{G A B A} \geq-65 \mathrm{mV}\right)$ and apparently normal dentate granule cells $\left(E_{G A B A}<65 \mathrm{mV}\right)$. The most depolarized $E_{\text {GABA }}$ appears in the overtly abnormal subpopulation of 1 week post-STEP cells after 12 IPSCS. Aii, Difference between final and initial $E_{G A B A}$ value after repeated of IPSCS. The greatest change in $E_{G A B A}$ appears in the apparently normal subpopulation of 1 week post-STEP cells. One-way repeated-measures ANOVA reveals a significant effect of STEP on the shift in $E_{\text {GABA }}$ ( $n=6$ cells per group; $p<0.05$ ). Bi, Positive shifts in $E_{G A B A}$ values are shown after multiple IPSCs in granule cells 2 weeks after STEP. Two weeks after STEP, the maximum $E_{\text {GABA }}$ in response to IPSC stimulation is greater than control. Bii, Difference between final and initial $E_{G A B A}$ value after repeated IPSCS. Two weeks after STEP, the change in $E_{G A B A}$ that appears is greater than that in control cells. One-way repeated-measures ANOVA reveals a significant effect of STEP on the shift in $E_{\text {GABA }}(n=6$ cells per group; $p<0.05)$. Ci, Mean $E_{G A B A}$ after repeated IPSCs in granule cells from chronically epileptic animals. The maximum $E_{G A B A}$ is similar to that in control. Analysis by one-way repeated-measures ANOVA indicates no difference from control ( $n=6$ cells per group; $p>0.05$ ). Cii, Difference between final and initial $E_{G A B A}$ value after repeated IPSCs. One-way repeated-measures ANOVA reveals a significant difference in the change in $E_{\mathrm{GABA}}$ from initial after multiple IPSCs ( $n=6$ cells per group; $p<0.05$ ), indicating that there are subtle differences in the way $E_{\mathrm{GABA}}$ shifts from baseline after multiple IPSCs in dentate granule cells from chronically epileptic animals.

protocol modified from Jin et al. (2005). $E_{\mathrm{GABA}}$ was first determined in each cell so that driving force could be normalized. The intensity of stimulation was adjusted to obtain a 200 pA IPSC in the initial trial, to further standardize the stimuli across groups. Each trial in a single cell was separated by 2 min to allow recovery. After a set of 1-12 IPSC stimuli at $0.2 \mathrm{~Hz}$, an additional IPSC was generated simultaneously with a ramp voltage command protocol $1 \mathrm{~s}$ after the final IPSC, and subtracted from a ramp generated in the absence of an IPSC to determine $E_{\mathrm{GABA}}$. This was repeated for each stimulus (from 1 to 12 IPSCs). The number of IPSCs in a given trial was chosen randomly to minimize any potential effects from the order of stimulus presentation. This protocol allowed us to observe how neurons respond to repetitive activation of IPSCs.

The results were then plotted in two ways. First, we plotted the number of IPSCs versus the mean $E_{\mathrm{GABA}}$ in each cell population (Fig. $2 A i, B i, C i$ ). Second, we plotted the number of IPSCs versus the change in $E_{\mathrm{GABA}}$ from baseline in each cell (Fig. 2Aii,Bii, Cii). In this way, we were able examine the absolute change in $E_{\mathrm{GABA}}$ as well as the average net change per cell in response to multiple IPSCs.

The relationship between IPSC number and change from baseline was then analyzed with respect to three criteria: 1) rise time of the IPSC/E $E_{\mathrm{GABA}}$ curve (Fig. $3 A$ ), 2) maximum change in $E_{\mathrm{GABA}}$ after 12 IPSCs (Fig. $3 B$ ), and 3) maximum $E_{\mathrm{GABA}}$ after 12 IPSCs (Fig. 3C). The maximum final $E_{\mathrm{GABA}}$ after 12 IPSCs was evident in the 1 week postSTEP subpopulation with an initially overtly abnormal $E_{\mathrm{GABA}}$ (Figs. 2Ai, 3C). We also found that $E_{\mathrm{GABA}}$ increased more rapidly (after fewer IPSCs) in this group than in control dentate granule cells (Figs. 2Aii, 3A). This group of cells is the one which we hypothesize to have the maximal $\mathrm{Cl}^{-}$regulatory deficits.

However, the apparently normal subgroup of 1 week post-STEP cells (with a resting $E_{\mathrm{GABA}}$ similar to controls) also had a significantly diminished ability to extrude $\mathrm{Cl}^{-}$ during sustained synaptic activity, as assessed by the repeated IPSC protocol. They showed the largest shift in $E_{\mathrm{GABA}}$ of all groups (Figs. $2 A i i, 3 B)$, and had a significantly greater final $E_{\mathrm{GABA}}$ than controls (Figs. $2 A i, 3 C$ ). In addition, $E_{\mathrm{GABA}}$ shifted much more rapidly in this group than in controls (Figs. 2Aii, 3A). Therefore, we conclude that dentate granule cells with an apparently normal $E_{\mathrm{GABA}} 1$ week post-STEP also had a significantly diminished capacity to appropriately regulate internal $\mathrm{Cl}^{-}$concentration. These cells have sufficient capacity to maintain $E_{\mathrm{GABA}}$ under resting conditions, but rapidly exhibit deficits during periods of activity.

By the 2 weeks post-STEP time point, although all neurons had an apparently normal resting $E_{\mathrm{GABA}}$, the rate of $E_{\mathrm{GABA}}$ increase remained faster than in control (Figs. $2 B i, 3 A$ ). As in the apparently normal subpopulation 1 week post-STEP, the maximum total shift in $E_{\mathrm{GABA}}$ (Figs. $2 B i i, 3 B$ ) was significantly greater than in control. The maximum absolute $E_{\mathrm{GABA}}$ (Figs. $2 \mathrm{Bi}, 3 \mathrm{C}$ ) was also significantly greater than in control. These cells were thus similar to those in the 1 week apparently normal subpopulation. We conclude from this data that, although all 2 week post-STEP neurons have the ability to maintain $E_{\mathrm{GABA}}$ at control levels under resting conditions, these cells still exhibit a significantly diminished capacity to regulate internal $\mathrm{Cl}^{-}$levels, which manifested itself strongly during repeated IPSC activation.

Dentate granule cells from epileptic animals appeared similar to control with the exception that they exhibited a more rapid $E_{\mathrm{GABA}}$ rise time in response to repeated IPSCs (Figs. 2Ci, 3A). Both absolute $E_{\mathrm{GABA}}$ and change in $E_{\mathrm{GABA}}$ measures were not significantly different from controls after the IPSC loading protocol (Figs. 2Ci,Cii, 3B,C). We conclude from this data that, although there may be some subtle kinetic differences in $\mathrm{Cl}^{-}$extrusion capacity in cells from chronically epileptic animals, for the most part, these neurons have restored their ability to regulate $E_{\mathrm{GABA}} 4-8$ weeks post-STEP, even under dynamic, active conditions.

$E_{\mathrm{GABA}}$ shifts in post-STEP granule cells are not attributable to newborn neuron recordings

One potential confound in our studies is the presence of a subpopulation of newborn dentate granule cells in the dentate gyrus, 


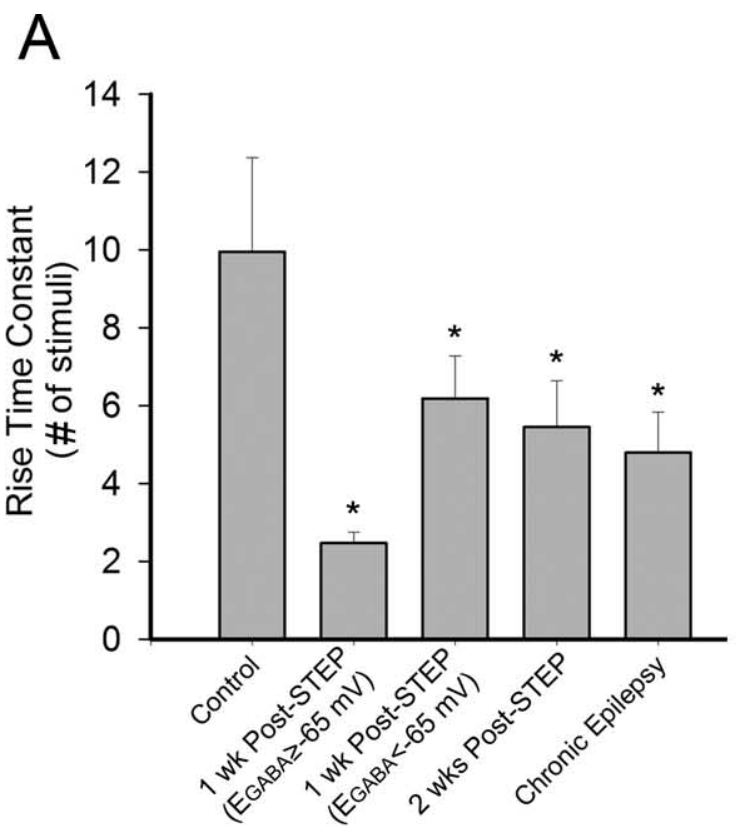

B
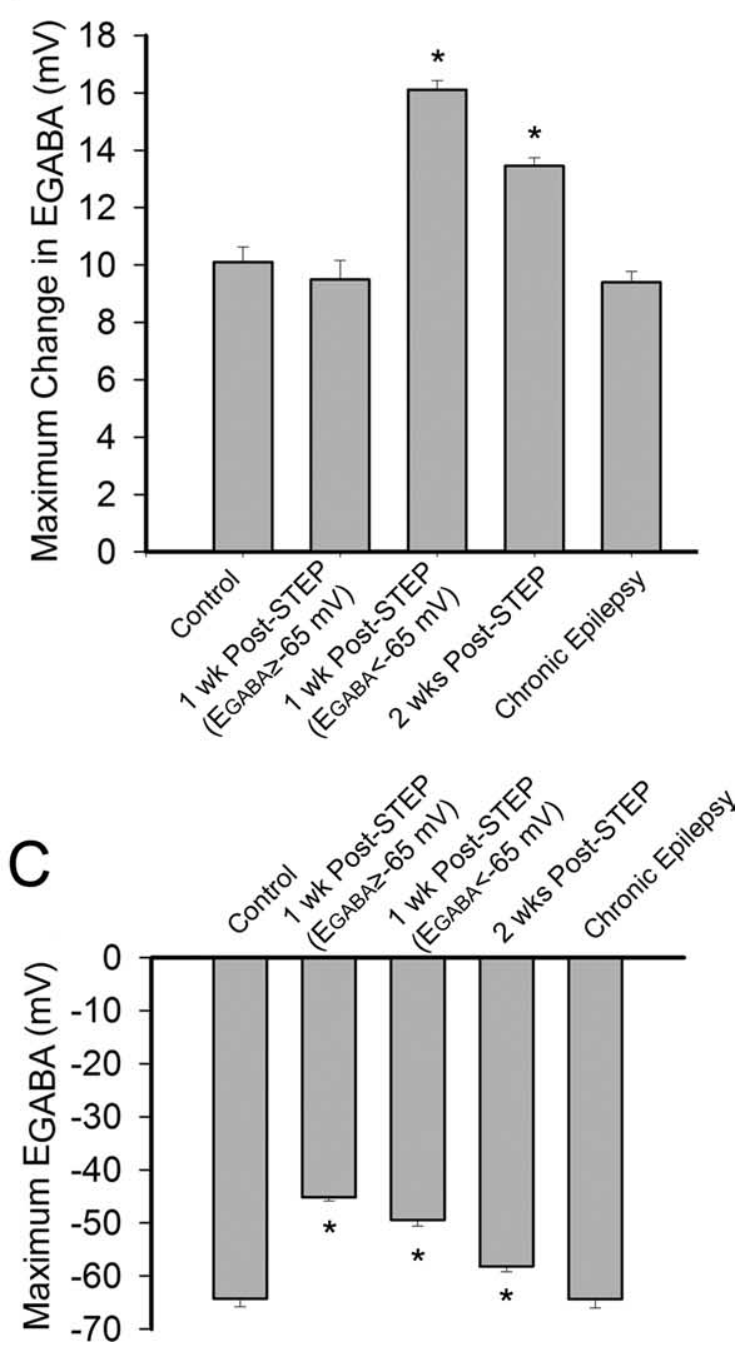

Figure 3. Kinetics of intracellular $\mathrm{Cl}^{-}$accumulation during repetitive IPSC activity are altered by STEP. $\boldsymbol{A}-\boldsymbol{C}$, Changes in $E_{\mathrm{GABA}}$ in each dentate granule cell subgroup were analyzed with respect to rise time, maximum final $E_{\mathrm{GABA}}$ after $12 \mathrm{IPSC}$, and maximum change in $E_{\mathrm{GABA}}$ after 12 IPSCs. $A$, Rise time for $E_{\mathrm{GABA}}$ shifts elicited by repetitive IPSCs decreases significantly after STEP. which appear in large numbers after STEP (Parent et al., 1997). Newborn granule cells in adult animals have a more positive $E_{\mathrm{GABA}}$ (Overstreet-Wadiche et al., 2005). If a subset of data were derived from newborn cell recordings, then the fact that these cells were early in development post-STEP, rather than surviving granule cells exhibiting plasticity in KCC2 expression, could explain the $E_{\mathrm{GABA}}$ shift. We do not believe this to be the case. Most adult born granule cells, including those generated after STEP, remain localized in the inner third of the granule cell layer (Bengzon et al., 1997; Parent et al., 1997). To avoid these cells in the present study, recordings were limited to cells in the outer third of the granule cell layer, in which virtually all neurons are mature. Another distinctive feature of newborn neurons is a high input resistance $\left(R_{\text {in }}\right)$, often $>1 \mathrm{G} \Omega$ (Schmidt-Hieber et al., 2004). To avoid recording from newborn neurons, only cells with $R_{\text {in }}<400$ $\mathrm{M} \Omega$ were included, consistent with mature granule cells. Based on these considerations, the shifted $E_{\mathrm{GABA}}$, altered $\mathrm{Cl}^{-}$regulation during synaptic activity, and changes in synaptic integration were all phenomena recorded in surviving, post-STEP mature granule cells. Therefore, these alterations represent a pathological form of plasticity rather than an epiphenomenon associated with recent cell birth.

\section{KCC2 expression decreases after STEP}

Substantial evidence exists demonstrating decreases in KCC2 and an associated positively shifted $E_{\mathrm{GABA}}$ after a wide range of neuronal injuries including physical deformation of neurons, temperature increases, oxidative stress, and pharmacological excitotoxicity (van den Pol et al., 1996; Cohen et al., 2002; Nabekura et al., 2002; Rivera et al., 2002, 2004; Khalilov et al., 2003; Toyoda et al., 2003; Jin et al., 2005; Bonislawski et al., 2007; Wake et al., 2007). In studies using antisense oligonucleotide treatment to reduce expression of KCC2, it was demonstrated that downregulation of KCC2 is mechanistically linked to a more positive $E_{\mathrm{GABA}}$ (Rivera et al., 1999). Shifts in KCC2 over time in in vivo models of epilepsy remain unknown. To follow the time course of KCC2 changes after STEP, we used Western blot analysis to compare KCC2 levels at varying times post-STEP (Fig. 4). As expected based on the perforated patch recordings, KCC2 levels were significantly downregulated at both the 1 and 2 week post-STEP time points (Fig. 4) (to $81.3 \pm 8.6$ and $78.3 \pm 4.1 \%$ of control levels, $t$ test, $n=4$ each, $p<0.05$ and $p<0.01$, respectively, quantified relative to tubulin levels). KCC2 signal intensity recovered to control levels in chronically epileptic animals (Fig. 4) (to $114.9 \pm 27.1 \%$ of control, $n=4, p>0.2$ ).

$\mathrm{Cl}^{-}$homeostasis can also be regulated by the protein NKCC1, which accumulates $\mathrm{Cl}^{-}$in cells. In immature neurons, NKCC1 is the dominant $\mathrm{Cl}^{-}$transporter and plays a major role in the elevated intracellular $\mathrm{Cl}^{-}$concentration seen early in development (Plotkin et al., 1997; Delpire et al., 1999; Yamada et al., 2004). In

\footnotetext{
The rise time constant was determined in terms of the number of IPSC stimuli. A lower time constant indicates a more rapid shift in $E_{\mathrm{GABA}}$ elicited by repetitive IPSCS. The rise time constant remains lower than in control for all cell groups after STEP. The most rapid rise time is seen in the overtly abnormal subgroup of 1 week post-STEP cells. $B$, The maximum change in $E_{\text {GABA }}$ in the apparently normal subpopulation of 1 week post-STEP cells as well as in the 2 weeks post-STEP cells is significantly higher than in control. The greatest maximum change in $E_{G A B A}$ is seen in the apparently normal subpopulation of 1 week post-STEP cells. C, Dentate granule cells from both of the 1 week post-STEP subpopulations and cells from the 2 weeks post-STEP population have a significantly higher maximum final $E_{\text {GABA }}$ after 12 IPSCs. The greatest final $E_{\text {GABA }}$ after 12 IPSCS is seen 1 week post-STEP in the overtly abnormal subpopulation of cells. ${ }^{*} p<0.05$, significant difference from control ( $t$ test; $n=6$ cells per group).
} 

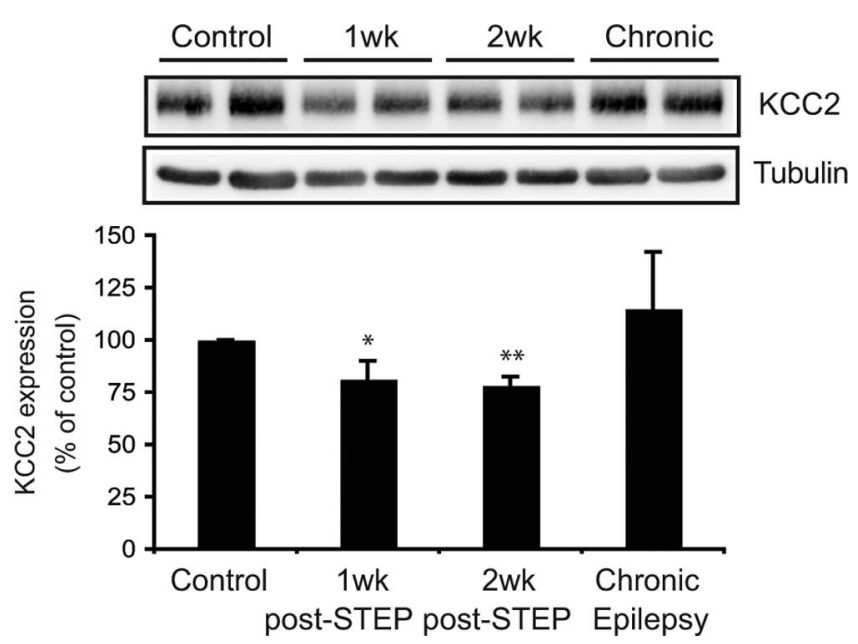

Figure 4. KCC2 expression is decreased in 1 and 2 week post-STEP. Rat dentate gyrus lysate $(20 \mu \mathrm{g})$ from control, 1 week post-STEP, 2 week post-STEP, and chronically epileptic animals ( $n=4$ each) was immunoblotted with anti-KCC2 and anti- $\alpha$-tubulin antibodies. The expression of KCC2 was normalized to $\alpha$-tubulin (KCC2/tubulin) and then plotted as percentage of control expression levels in the histogram comparing groups $\left({ }^{*} p<0.05,{ }^{* *} p<0.01\right.$, Student's t test).

preliminary immunohistochemical studies, we were unable to detect the presence of NKCC1 either in control or post-STEP slices, and so could not assess the possible role of this transporter in regulating $E_{\mathrm{GABA}}$. This lack of staining is consistent with the reported minimal role for this transporter in adult neurons (Martina et al., 2001; Marty et al., 2002).

\section{Furosemide blockade of KCC2 in control tissue mimics STEP} effects on $E_{\mathrm{GABA}}$

Given that the dominant $\mathrm{Cl}^{-}$transporter in adult neurons is $\mathrm{KCC} 2$, and that this protein is downregulated after STEP, blockade of KCC2 function in control cells should mimic findings evident in post-STEP cells. Furosemide is a loop diuretic that blocks the activity of KCC2. To test the role of KCC2 functionally, we blocked the transporter with furosemide (0.1-1.0 mM). Bathing control slices in $0.1 \mathrm{~mm}$ furosemide did not change resting $E_{\mathrm{GABA}}\left(E_{\mathrm{GABA}}=-75.6 \pm 0.8 \mathrm{mV}, n=4\right.$ cells $)$. Higher concentrations of furosemide $(1.0 \mathrm{mM})$ elicited a depolarizing shift in resting $E_{\mathrm{GABA}}$ in control cells (Fig. $\left.5 A\right)(t$ test, $p<0.05)$. In addition, application of furosemide $(1 \mathrm{mM})$ to 1 week post-STEP neurons elicited no additional shift in $E_{\mathrm{GABA}}$, reflecting an occlusive interaction between furosemide and post-STEP effects on $E_{\mathrm{GABA}}$ (Fig. 5A). This supports the hypothesis that these two manipulations have a shared underlying mechanism responsible for shifts in $E_{\mathrm{GABA}}$, reduced function of KCC2. We examined further the effects of furosemide on the kinetics of $\mathrm{Cl}^{-}$regulation by repeating the multiple IPSC protocol experiments described above.

Because smaller scale reduction in KCC2 function may be associated with normal resting $E_{\mathrm{GABA}}$, but compromised ability to regulate $\mathrm{Cl}^{-}$during repetitive inhibitory synaptic activity, we determined whether these activity-dependent effects could be reproduced with varying doses of furosemide. As in post-STEP cells, we found that a resting $E_{\mathrm{GABA}}$ similar to that in control can mask a decreased ability to regulate $\left[\mathrm{Cl}^{-}\right]_{\text {in }}$ after repeated IPSCs. The protocol used was identical to previously described experiments (Fig. 2). The results are shown as a change in $E_{\mathrm{GABA}}$ from the initial resting value (Fig. $5 B$ ). When $0.1 \mathrm{~mm}$ furosemide was applied to control cells, faster rise times were observed (Fig. $5 C$ ) (significantly different from controls, $p<0.05$ ) and decreased further during treatment with 0.5 and $1 \mathrm{~mm}$ furosemide (significantly different from controls, $p<0.05$ ). When $1.0 \mathrm{~mm}$ furosemide was applied, $E_{\mathrm{GABA}}$ failed to return to normal after repeated IPSCs (data not shown), suggesting complete blockade of KCC2 function. These data demonstrate that both the static and dynamic $E_{\mathrm{GABA}}$ effects evident in apparently normal and overtly abnormal post-STEP neurons can be mimicked by furosemidemediated low- and high-level blockade of KCC2 function, respectively. This further supports a role for graded degrees of KCC2 downregulation mediating depression of $\mathrm{Cl}^{-}$homeostasis in granule cells from post-STEP animals.

\section{Depolarized $E_{\mathrm{GABA}}$ increases granule cell excitability by altering synaptic integration}

One important consequence of depolarizing GABA currents is the potential for GABA induced action potentials (Dzhala and Staley, 2003; Gulledge and Stuart, 2003). $E_{\mathrm{GABA}}$ in all post-STEP cells was not sufficiently depolarizing to reach action potential threshold during an IPSP (from a $V_{\mathrm{m}}$ of $-65 \mathrm{mV}$ ). However, the depolarizing effect of GABA may be sufficient to facilitate action potential generation if the IPSP is paired with a subthreshold EPSP. If this is the case, the positive shift in $E_{\mathrm{GABA}}$ after STEP would alter synaptic integration in dentate granule cells.

We assessed whether cells would generate action potentials when an EPSP was paired with an IPSP (Fig. 6). Because glutamate receptors were blocked to isolate IPSPs, IPSPs were paired with an artificial EPSP (aEPSP), generated by current injection through the recording electrode. We found that a novel temporal window for generating action potential exists in these post-STEP cells. If an aEPSP occurred during the nonconducting phase of the depolarizing event, an action potential was generated; if it occurred during the earlier $\mathrm{Cl}^{-}$conducting phase, the events summed sublinearly, and no action potential was generated (Fig. $6 \mathrm{~A}$ ). We plotted the action potential firing probability as it varied when an aEPSP was preceded, at varying intervals, by an IPSP. In each cell, the amplitude of the aEPSP was calibrated so that the probability of reaching threshold was below $0.20(0.18 \pm 0.02$, $n=4$ overtly abnormal 1 -week post STEP cells, 6 control cells). When the depolarizing IPSP preceded the aEPSP by $50-150 \mathrm{~ms}$, the probability of action potential generation was significantly increased (Fig. 6B) ( $t$ test, $p<0.05)$. Therefore, during a depolarizing IPSP, there is a $100 \mathrm{~ms}$ window during which excitation is facilitated. When the aEPSP was elicited during the conducting phase of the IPSP, within 20-30 ms of IPSP onset, action potential firing was significantly impaired (Fig. $6 A, B$ ). To confirm that the enhanced action potential probability window was related to the nonconducting phase of the IPSP, we paired two subthreshold aEPSPs and found that, as expected, the PSPs summated linearly, and action potentials were generated without respect to timing (data not shown). Pairing the aEPSP with a hyperpolarizing IPSP in control cells decreased the probability of action potential generation at all time points (Fig. 6A,B). Therefore, during the latent period, GABA can depolarize dentate granule cells, and also facilitate the generation of action potentials.

\section{VSD recordings of dentate gyrus function in control and post-STEP slices}

To assess further the consequences of dentate granule cell $E_{\mathrm{GABA}}$ shifts on function of the hippocampus in post-STEP animals, we performed VSD imaging in slices prepared from control and 1 week post-STEP animals. VSD studies allow the spatiotemporal dynamics of circuit activation to be studied at high spatial and 


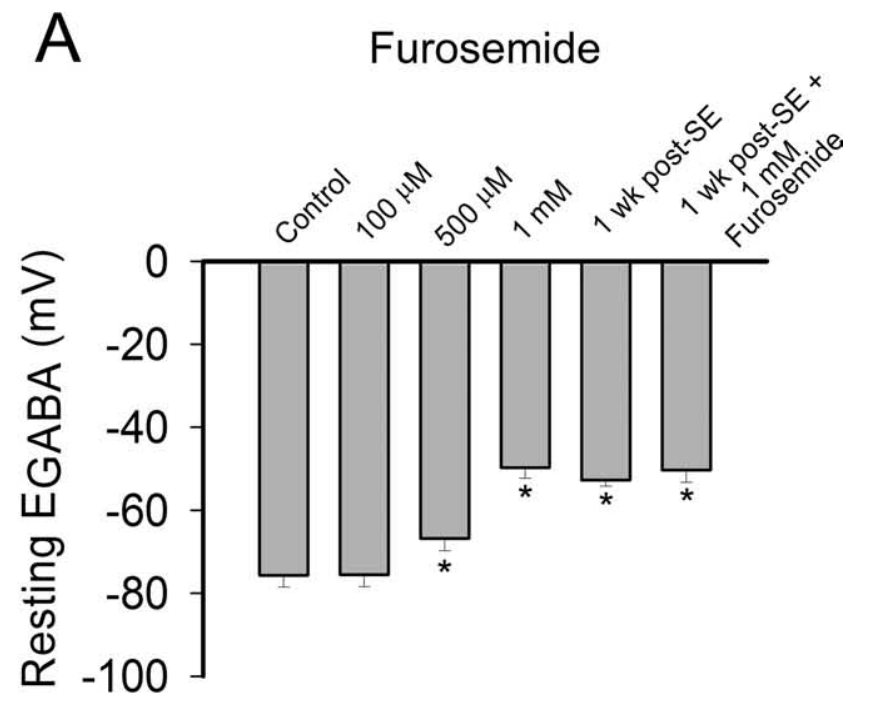

B

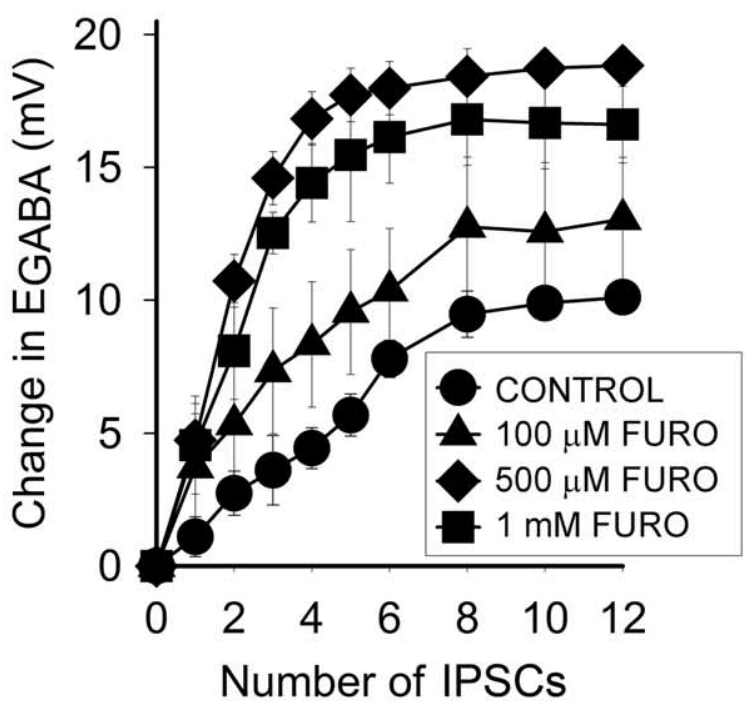

C

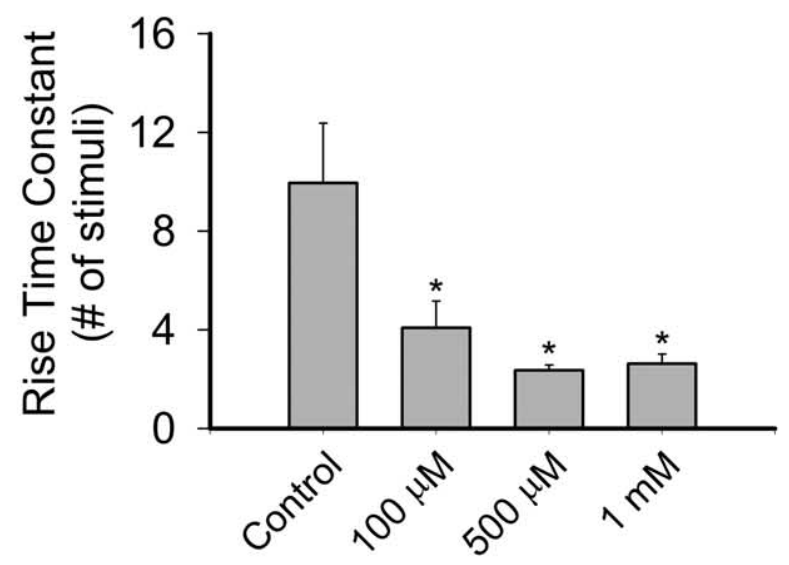

Furosemide

Figure 5. Changes in dentate granule cell $E_{G A B A}$ post-STEP are mimicked by furosemide, and furosemide and post-STEP effects on $E_{\text {GABA }}$ interact occlusively, implicating common mechanisms. $A-C$, Blockade of $\mathrm{KCC} 2$ with varying concentrations of furosemide gradually diminishes temporal resolution, providing a simultaneous readout of circuit response to a synaptic input, subsequent integration, and activation of efferent targets (cf. Ang et al., 2005, 2006). In control slices, the dentate gyrus strongly filtered afferent input from the entorhinal cortex, allowing little activation of area CA3 despite powerful, widespread activation of the dentate gyrus stratum moleculare by the stimulus (Fig. 7A) (supplemental Fig. $1 B, D, \mathrm{~F}$, available at www.jneurosci.org as supplemental material), as we have seen previously (Ang et al., 2006; Coulter and Carlson, 2007). This "gatekeeper" function of the dentate gyrus has been hypothesized to be critical in regulating propagation of epileptic activity within the limbic system (Heinemann et al., 1992; Lothman et al., 1992; Behr et al., 1998) and is attributable in large part to GABAergic feedforward inhibition activated by perforant path stimulation (Coulter and Carlson, 2007). The filtering function of the dentate was markedly compromised in slices prepared from animals 1 week post-STEP, in which significant activation of area CA3 was evident after perforant path stimulation (to $209 \%$ of control levels) (Fig. 7B). In addition to increased throughput to $\mathrm{CA} 3$, there was a significant prolongation of perforant path activation of the dentate gyrus, without effects on the maximum (Fig. 7D). This prolongation may reflect changes in the feedforward GABAergic synaptic potential activated by the stimulus, which is now strongly depolarizing attributable to altered transmembrane chloride gradients (Fig. 1). In control slices exposed to furosemide $(1 \mathrm{~mm})$, both the decrease in throughput and the prolongation of the perforant path response effects could be mimicked by repetitive activation of the perforant path at 20 $\mathrm{Hz}$, a frequency designed to maximize activation via depolarizing IPSPs (compare with Fig. 6). Under these conditions, areal analysis reveals significant increased activation of hilus and CA3 after furosemide exposure, $p<0.05, n=3$ ) (supplemental Fig. $1 B, E, F$, available at www.jneurosci.org as supplemental material). Furthermore, furosemide application to 1 week post-STEP slices exhibited little additional effect on throughput of perforant path stimulation to area CA3 (or on the prolonged perforant path response), reflecting an occlusive interaction between post-STEP alterations and furosemide effects (Fig. $7 B-E$ ). This provides support for the hypothesis that these two manipulations may share a similar underlying mechanism to compromise function of the dentate gyrus, reduction of KCC2 function.

\section{Discussion}

The principal findings of this study are that, in hippocampal dentate granule cells, for 2 weeks after STEP, $E_{\mathrm{GABA}}$ becomes more positive, accompanied by decreased expression of the $\mathrm{Cl}^{-}$

\footnotetext{
$\leftarrow$

dentate granule cell capacity to regulate intracellular $\mathrm{Cl}^{-}$, measured using $E_{\mathrm{GABA}}$. As in the post-STEP cell groups, $E_{G A B A}$ was measured at rest and after repetitive IPSCS, after bath application of $100 \mu \mathrm{m}, 500 \mu \mathrm{m}$, and $1.0 \mathrm{~mm}$ furosemide. $\boldsymbol{A}$, Furosemide causes an increase in resting $E_{G A B A}$ only when high concentrations $(0.5-1.0 \mathrm{~mm})$ are applied. When furosemide $(1 \mathrm{~mm})$ is applied to 1 week post-STEP neurons, it produces no additional effect on $E_{\mathrm{GABA}^{\prime}}$ demonstrating that post-STEP and furosemide effects on $E_{G A B A}$ share mechanisms. $\boldsymbol{B}$, As in post-STEP cells, differences in $E_{G A B A}$ shifts after repetitive IPSCs are evident. These differences are enhanced by increasing concentrations of furosemide. The repetitive IPSC protocol during furosemide application was identical to that in Figure 2. Analysis by one-way ANOVA with repeated measures reveals a significant effect of furosemide on repetitive IPSC-induced shift in $E_{\mathrm{GABA}}$ ( $n=4$ cells per group; $p<0.05)$. C, Furosemide alters rise time relative to control. The IPSC number $/ E_{G A B A}$ shift rise time after application of $100 \mathrm{~mm}$ furosemide is not significantly different from that observed in the apparently normal subpopulation of cells 1 week post-STEP. Both the 500 and 1 $\mathrm{mm}$ concentrations of furosemide result in rise time values similar to those seen in the overtly abnormal subpopulation of cells 1 week post-STEP. ${ }^{*} p<0.05$, significant difference from control ( $t$ test; $n=6$ control cells and 4 cells per each furosemide containing group).
} 

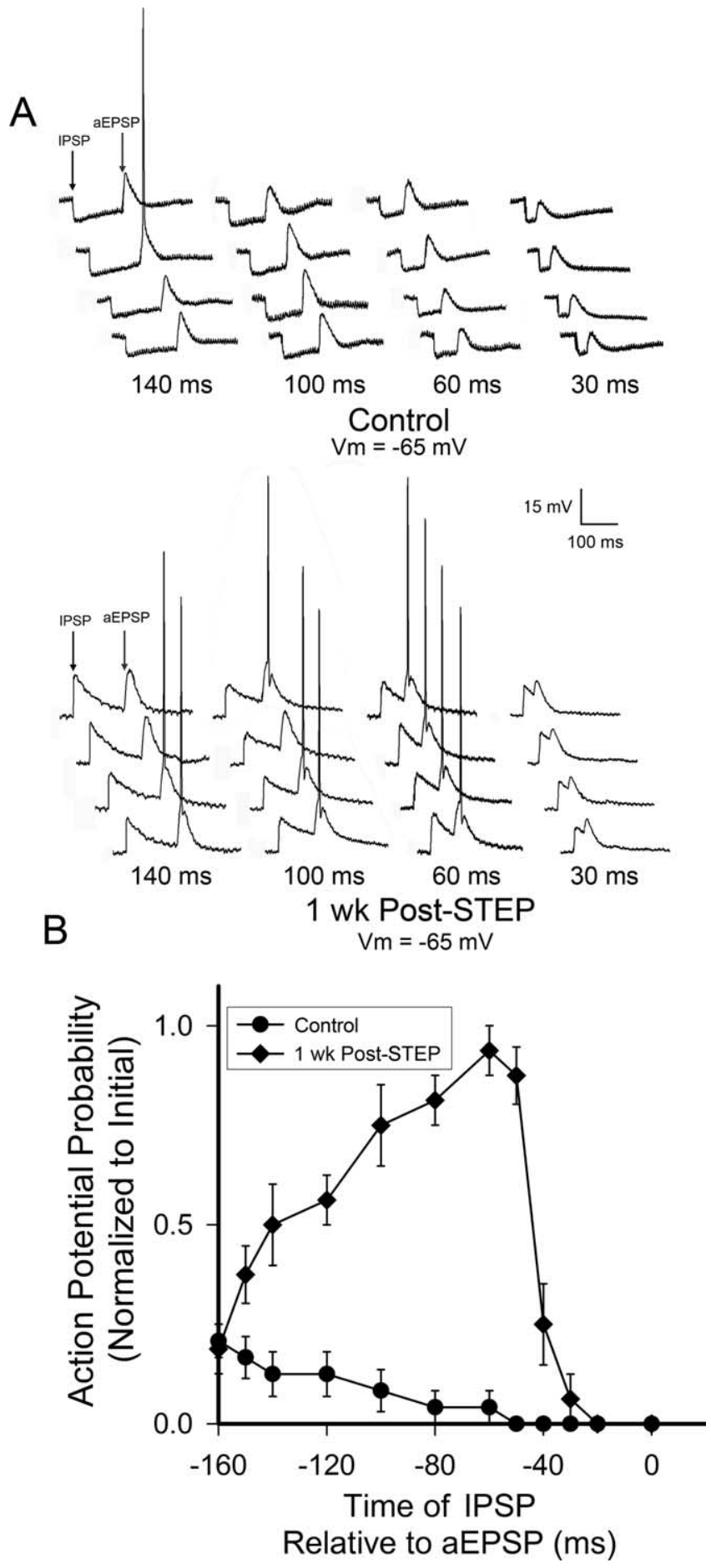

Figure 6. Depolarizing GABAergic PSPs contribute to action potential induction by altering synaptic integration. $A, B$, A subthreshold GABAergic IPSP and an aEPSP can be paired to generate an action potential. This introduces a novel mechanism for action potential generation 1 week after STEP. A, Sample traces show pairing of events $(140,100,60$, and $30 \mathrm{~ms}$ apart) in control cells and in the overtly abnormal 1 week post-STEP cells. $\boldsymbol{B}$, Within a $100 \mathrm{~ms}$ time window, a depolarizing GABAergic PSP increases the probability of an action potential. On average, the probability that the subthreshold aEPSP generated an action potential was $0.184 \pm 0.019$. This probability increases when the interpulse interval is between 150 and 50 $\mathrm{ms}$. When the GABAergic PSP precedes the aEPSP by $20-30 \mathrm{~ms}$ or less, the probability of action potential firing is depressed. Hyperpolarizing GABAergic PSPs consistently decreased the probability of action potentials in control cells. Analysis by one-way ANOVA with repeated measures shows a significant effect of interpulse timing on action potential probability in each case $(n=$ 6 control cells, 41 -week post-STEP cells; $p<0.05$ ). extruding transporter, KCC2. $E_{\mathrm{GABA}}$ returns to control levels at times 2 weeks or longer after STEP, accompanied by restoration in KCC2 expression. During this 2 week period of a shifted $E_{\mathrm{GABA}}$, granule cells exhibit a decreased ability to regulate intracellular $\mathrm{Cl}^{-}$levels during inhibitory synaptic activity, which results in an enhanced depolarizing shift in $E_{\mathrm{GABA}}$. Both the shift in $E_{\mathrm{GABA}}$, as well as the subset of cells in which $E_{\mathrm{GABA}}$ is maintained but cells respond with aberrant, larger depolarizing shifts in $E_{\mathrm{GABA}}$ during inhibitory synaptic stimulation, could be mimicked by application of high or low concentrations of the KCC2 blocker, furosemide, respectively. Furthermore, application of furosemide to post-STEP neurons resulted in occlusive (nonadditive) effects on $E_{\mathrm{GABA}}$, further implicating shared mechanisms of STEP and furosemide on $E_{\mathrm{GABA}}$. Therefore, the emergence of multiple dentate granule cell populations, which differ in their $\mathrm{Cl}^{-}$regulation, appears to be attributable to graded reductions in KCC2 function. The post-STEP shift in $E_{\mathrm{GABA}}$ also alters granule cell excitability. During depolarizing IPSPs in post-STEP neurons, EPSPs are more likely to generate action potentials. By altering synaptic integration in this way, dentate granule cells excitability is enhanced, potentially compromising the filter function of the dentate gyrus. This was assessed directly in VSD imaging studies of dentate gyrus function. The ability of the dentate gyrus to filter afferent input was compromised in slices prepared from 1 week post-STEP animals, this effect could be mimicked by furosemide application, and post-STEP and furosemide effects on dentate gyrus function interacted occlusively, supporting the concept that both are attributable to compromised function of KCC2.

\section{Depolarized $E_{\mathrm{GABA}}$ and decreased KCC2 after STEP}

Although $E_{\mathrm{GABA}}$ is shifted both $24 \mathrm{~h}$ and 1 week after STEP, the distribution of this shift differs between the two groups. The shift is uniformly distributed among dentate granule cells at $24 \mathrm{~h}$, whereas only a subpopulation of cells show a positively shifted $E_{\mathrm{GABA}}$ after 1 week. This is similar to what has been reported in subicular pyramidal cells recorded in human epileptic tissue, in which only a subset $(22 \%)$ of cells show a GABA-dependent excitation (Cohen et al., 2002; Huberfeld et al., 2007). Cells may recover at different rates after STEP, resulting in a smaller population of affected cells 1 week post-STEP. Alternatively, the acute effects of STEP may be attributable to the release of extracellular modulators such as BDNF (Rivera et al., 2004), which regulate KCC2 membrane expression and phosphorylation state in all cells (Wake et al., 2007). In contrast, the longer lasting effects may involve signaling cascades regulating transcription or translation of KCC2 predominantly in a subset of cells.

\section{Unique, cell morphology-dependent sensitivity of dentate granule cells to alterations in $\mathrm{Cl}^{-}$regulation}

Most studies examining activity- or stress-induced changes in $\mathrm{Cl}^{-}$homeostasis have been conducted in pyramidal neurons (Khalilov et al., 2003; Rivera et al., 2004; Jin et al., 2005; Wake et al., 2007). Based on their differing anatomy, it is likely that the smaller size of dentate granule cells makes them particularly sensitive to $\mathrm{Cl}^{-}$loading (and therefore to alterations in $\mathrm{Cl}^{-}$homeostasis) relative to pyramidal neurons. We estimate that an average granule cell soma has a $10 \mu \mathrm{m}$ diameter and contains an $8 \mu \mathrm{m}$ diameter nucleus. Assuming a spherical cell body and that there is a diffusion barrier between the somatic and nuclear cytoplasmic compartments, the fluid volume under the cell membrane available for $\mathrm{Cl}^{-}$dilution is $\sim 250 \mu \mathrm{m}^{3}$. In comparison, we estimate a CA1 pyramidal cell diameter to be $20 \mu \mathrm{m}$ and, assum- 
ing it also has an $8 \mu \mathrm{m}$ diameter nucleus, a somatic cytoplasmic volume of $\sim 4000$ $\mu \mathrm{m}^{3}$, a 16 -fold increase compared with granule cells. Ignoring the nucleus, cell volume is fourfold higher in pyramidal neurons compared with granule cells.

Given that similar $\mathrm{Cl}^{-}$loads would dilute into differing cytoplasmic volumes in the two cell types and therefore differentially alter $\left[\mathrm{Cl}^{-}\right]_{\mathrm{i}}$, our repetitive IPSC protocol should not shift $E_{\mathrm{GABA}}$ to the same extent in the larger CA1 pyramidal cells. In fact, we conducted this experiment in control CA1 cells, and found that $E_{\mathrm{GABA}}$ was not changed by 12, 200 pA IPSCs (a $1.1 \pm$ $0.1 \mathrm{mV}$ shift, not significant, paired $t$ test, $n=3$ cells, data not shown). This is in contrast to a $10.1 \pm 0.5 \mathrm{mV} E_{\mathrm{GABA}}$ shift in control dentate granule cells exposed to the same protocol (Fig. 2). Dentate granule cells, then, are more sensitive to activitydependent disruption in $\mathrm{Cl}^{-}$regulation than larger cells. Similar reductions in KCC2 expression may result in proportionally greater deficits in the ability of dentate granule cells to maintain $\mathrm{Cl}^{-}$ homeostasis.

\section{Synaptic integration in dentate granule cells after STEP}

Although dentate granule cell $E_{\mathrm{GABA}}$ is positively shifted after STEP, this was insufficient for depolarizing IPSPs alone to generate action potentials. The shifted $E_{\mathrm{GABA}}$ was still below action potential threshold, and therefore activation of $\mathrm{GABA}_{\mathrm{A}}$ receptors never depolarized neurons sufficiently to activate cell firing. However, activation of depolarizing IPSPs did alter synaptic integration, enhancing excitability of affected dentate granule cells. During a depolarizing IPSP, there are two phases. Early during the IPSP, GABA activates $\mathrm{GABA}_{\mathrm{A}}$ receptors, which generate a large conductance and a depolarization. This is the "conducting" phase of the IPSP. Later during the IPSP, $\mathrm{GABA}_{\mathrm{A}}$ receptors deactivate or desensitize, and the cell then repolarizes at a rate determined by passive membrane properties. This is the "nonconducting" phase of the IPSP. During the conducting phase of a depolarizing IPSP (within 20-30 ms of onset), an EPSP was unlikely to induce action potential firing because of the shunting conductance mediated by open $\mathrm{GABA}_{\mathrm{A}}$ receptors. However, during the nonconducting phase, the IPSP-mediated depolarization and the EPSP summed, increasing the probability of action potential firing (Fig. 6). Similar findings have been published demonstrating integration of depolarizing IPSPs and EPSPs in hypothalamic and neocortical neurons, in which $E_{\mathrm{GABA}}$ is also subthreshold for initiating action potentials (Gao et al., 1998; Gulledge and Stuart, 2003).

Shifts in $E_{\mathrm{GABA}}$ and associated alterations in EPSP/IPSP integration (Fig. 6) play a significant role in regulating the filter func-
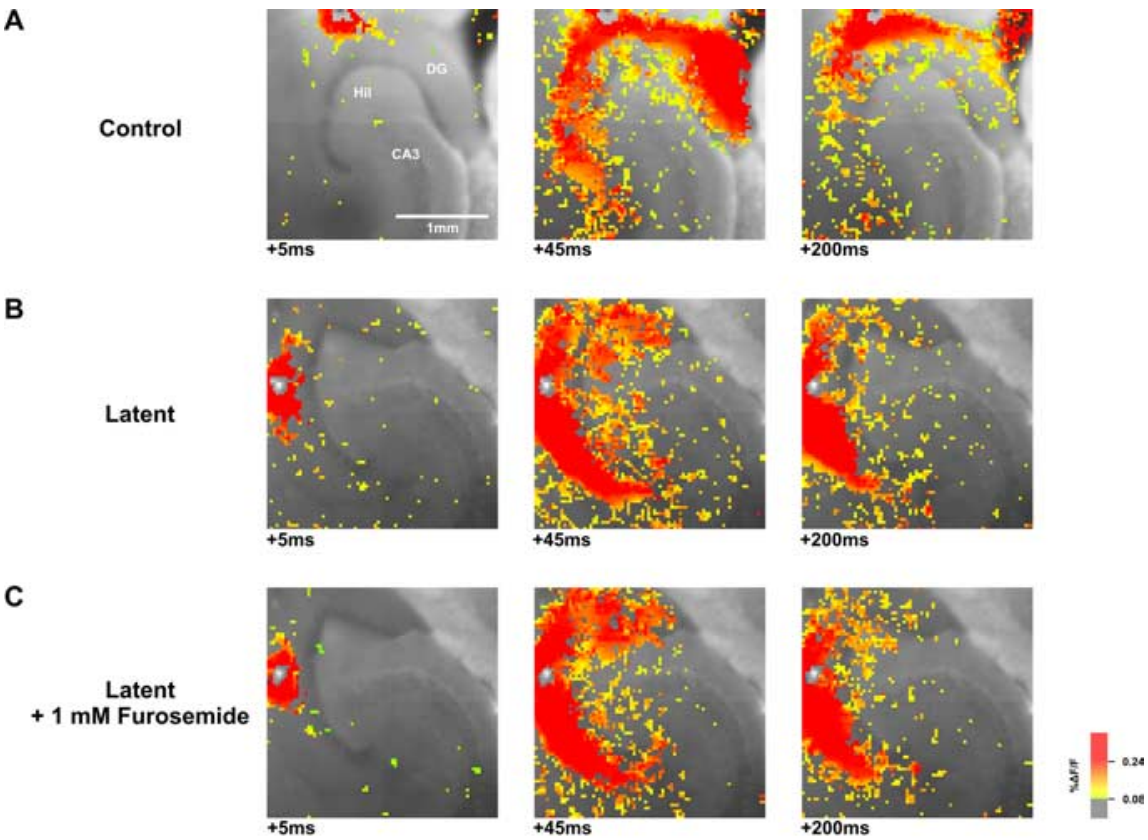

D

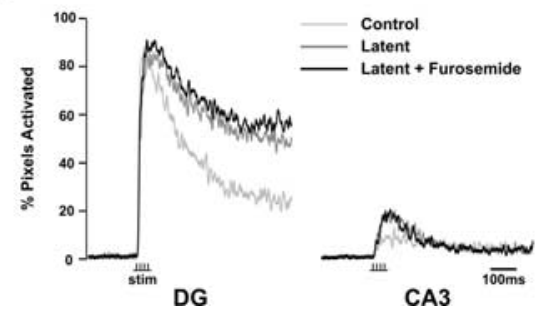

Figure 7. Dentate gyrus filtering of afferent input is compromised 1 week after STEP, and STEP and furosemide effects interact occlusively. A-C, VSD recording snapshots at the onset (5 ms after stimulus; left column), peak (middle column; note that the column) during the perforant path response, illustrating activation of the dentate gyrus (4 pulses at $100 \mathrm{~Hz}$ ) in control $(\boldsymbol{A}), 1$ week post-STEP $(\boldsymbol{B})$, and 1 week post-STEP plus furosemide (1 mM) slices ( $\boldsymbol{C}$. Note that the dentate gyrus filters input in controls (CA3 note expanded area of activated pixels), and furosemide has no additional effect on filtering function in 1 week post-STEP slices. , Areal analysis quantifying STEP and STEP plus furosemide effects on dentate gyrus filter function. Note that there is equivalent controls ( $\sim 10 \%$ of pixels activate), CA3 activation increases markedly after STEP ( $\sim 20 \%$ of pixels activate), and furosemide does 列 and dividing it by the degree of activation of the dentate gyrus. Note that CA3 activation increases to $209 \%$ of control levels in post-STEP slices $\left({ }^{*} p<0.05\right.$ ) and that furosemide has no additional effect (no significant difference between STEP and STEP plus furosemide treatment; $n=6$ ). tion of the dentate gyrus, a function that critically depends on the efficacy of inhibition (Coulter and Carlson, 2007), and has been hypothesized to be a major regulatory site in epilepsy (Heinemann et al., 1992; Lothman et al., 1992). Using VSD imaging, which allows afferent activation, integration, and output of circuits to be monitored simultaneously at high spatial and temporal resolution (Ang et al., 2006), we determined that the filter function of the dentate was significantly compromised. Perforant path activation normally results in minimal activation of efferent targets of the dentate gyrus (hilus and area CA3) in slices prepared control animals (Fig. 7A) (supplemental Fig. 1, available at www.jneurosci.org as supplemental material) (Ang et al., 2006), but triggered markedly elevated levels of activation of these struc- 
tures in slices prepared from animals 1 week post-STEP (CA3 throughput increases to $209 \%$ of control levels) (Fig. 7B). This effect was mimicked by furosemide application, particularly when the circuit was activated at frequencies during which aberrant EPSP/IPSP integration attributable to $E_{\mathrm{GABA}}$ shifts was maximal (compare with Fig. 6) $(10-20 \mathrm{~Hz}, p<0.05)$ (supplemental Fig. 1, available at www.jneurosci.org as supplemental material). Furthermore, post-STEP and furosemide actions on dentate filtering summed sublinearly, i.e., were occlusive (Fig. $7 B, C, E$ ). This further demonstrates that these phenomena share an underlying mechanism, altered $E_{\mathrm{GABA}}$. Therefore, shifts in $E_{\mathrm{GABA}}$ in post-STEP granule cells enhance excitability, and alter the function of the dentate gyrus in a manner facilitating pathological activity.

The time during which $E_{\mathrm{GABA}}$ is positively shifted in dentate granule cells coincides with the latent period between STEP and the onset of spontaneous recurrent seizures (chronic epilepsy). The dentate gyrus is hypothesized to function as an inhibitory gate, restricting synchronous activation of the hippocampus. This may be particularly important in resisting seizure propagation in the limbic system (Heinemann et al., 1992; Lothman et al., 1992). After STEP, the entorhinal cortex generates repetitive bursts, which bombard the dentate gyrus (Kobayashi et al., 2003; Bragin et al., 2004; Harvey and Sloviter, 2005). If dentate gate function is compromised by the emergence of depolarizing IPSPs, as suggested by our synaptic integration studies, then the likelihood that synchronous activity is relayed into hippocampus becomes markedly elevated. This bursting activity has the potential to damage fragile neurons within the hilus, CA3, and CA1, leading to neuronal loss, plasticity and sclerosis, hallmarks of epilepsy. Therefore, downregulation of KCC2 in post-STEP granule cells may constitute an important mechanism linking injurious stimuli to the subsequent emergence of epilepsy, making it a potentially viable therapeutic target to prevent epilepsy in at risk individuals.

\section{References}

Ang CW, Carlson GC, Coulter DA (2005) Hippocampal CA1 circuitry dynamically gates direct cortical inputs preferentially at theta frequencies. J Neurosci 25:9567-9580.

Ang CW, Carlson GC, Coulter DA (2006) Massive and specific dysregulation of direct cortical input to the hippocampus in temporal lobe epilepsy. J Neurosci 26:11850-11856.

Annegers JF, Grabow JD, Groover RV, Laws Jr ER, Elveback LR, Kurland LT (1980) Seizures after head trauma: a population study. Neurology 30:683-689.

Behr J, Lyson KJ, Mody I (1998) Enhanced propagation of epileptiform activity through the kindled dentate gyrus. J Neurophysiol 79:1726-1732.

Ben-Ari Y, Cherubini E, Corradetti R, Gaiarsa JL (1989) Giant synaptic potentials in immature rat CA3 hippocampal neurones. J Physiol (Lond) 416:303-325.

Bengzon J, Kokaia Z, Elmer E, Nanobashvili A, Kokaia M, Lindvall O (1997) Apoptosis and proliferation of dentate gyrus neurons after single and intermittent limbic seizures. Proc Natl Acad Sci USA 94:10432-10437.

Bonislawski DP, Schwarzbach EP, Cohen AS (2007) Brain injury impairs dentate gyrus inhibitory efficacy. Neurobiol Dis 25:163-169.

Bragin A, Wilson CL, Almajano J, Mody I, Engel Jr J (2004) High-frequency oscillations after status epilepticus: epileptogenesis and seizure genesis. Epilepsia 45:1017-1023.

Cavalheiro EA, Leite JP, Bortolotto ZA, Turski WA, Ikonomidou C, Turski L (1991) Long-term effects of pilocarpine in rats: structural damage of the brain triggers kindling and spontaneous recurrent seizures. Epilepsia 32:778-782.

Cohen I, Navarro V, Clemenceau S, Baulac M, Miles R (2002) On the origin of interictal activity in human temporal lobe epilepsy in vitro. Science 298:1418-1421.
Collins RC, Tearse RG, Lothman EW (1983) Functional anatomy of limbic seizures: focal discharges from medial entorhinal cortex in rat. Brain Res 280:25-40.

Coulter DA, Carlson GC (2007) Functional regulation of the dentate gyrus by GABA-mediated inhibition. Prog Brain Res 163:235-243.

Delpire E, Lu J, England R, Dull C, Thorne T (1999) Deafness and imbalance associated with inactivation of the secretory $\mathrm{Na}-\mathrm{K}-2 \mathrm{Cl}$ co-transporter. Nat Genet 22:192-195.

Dzhala VI, Staley KJ (2003) Excitatory actions of endogenously released GABA contribute to initiation of ictal epileptiform activity in the developing hippocampus. J Neurosci 23:1840-1846.

Gao XB, Chen G, van den Pol AN (1998) GABA-dependent firing of glutamate-evoked action potentials at AMPA/kainate receptors in developing hypothalamic neurons. J Neurophysiol 79:716-726.

Gibbs III JW, Shumate MD, Coulter DA (1997) Differential epilepsyassociated alterations in postsynaptic GABA(A) receptor function in dentate granule and CA1 neurons. J Neurophysiol 77:1924-1938.

Gulledge AT, Stuart GJ (2003) Excitatory actions of GABA in the cortex. Neuron 37:299-309.

Halasy K, Somogyi P (1993) Subdivisions in the multiple GABAergic innervation of granule cells in the dentate gyrus of the rat hippocampus. Eur J Neurosci 5:411-429.

Han ZS, Buhl EH, Lorinczi Z, Somogyi P (1993) A high degree of spatial selectivity in the axonal and dendritic domains of physiologically identified local-circuit neurons in the dentate gyrus of the rat hippocampus. Eur J Neurosci 5:395-410.

Harvey BD, Sloviter RS (2005) Hippocampal granule cell activity and c-Fos expression during spontaneous seizures in awake, chronically epileptic, pilocarpine-treated rats: implications for hippocampal epileptogenesis. J Comp Neurol 488:442-463.

Heinemann U, Beck H, Dreier JP, Ficker E, Stabel J, Zhang CL (1992) The dentate gyrus as a regulated gate for the propagation of epileptiform activity. Epilepsy Res Suppl 7:273-280.

Hollrigel GS, Ross ST, Soltesz I (1998) Temporal patterns and depolarizing actions of spontaneous $\mathrm{GABA}_{\mathrm{A}}$ receptor activation in granule cells of the early postnatal dentate gyrus. J Neurophysiol 80:2340-2351.

Huberfeld G, Wittner L, Clemenceau S, Baulac M, Kaila K, Miles R, Rivera C (2007) Perturbed chloride homeostasis and GABAergic signaling in human temporal lobe epilepsy. J Neurosci 27:9866-9873.

Jin X, Huguenard JR, Prince DA (2005) Impaired $\mathrm{Cl}^{-}$extrusion in layer $\mathrm{V}$ pyramidal neurons of chronically injured epileptogenic neocortex. J Neurophysiol 93:2117-2126.

Khalilov I, Holmes GL, Ben-Ari Y (2003) In vitro formation of a secondary epileptogenic mirror focus by interhippocampal propagation of seizures. Nat Neurosci 6:1079-1085.

Kobayashi M, Wen X, Buckmaster PS (2003) Reduced inhibition and increased output of layer II neurons in the medial entorhinal cortex in a model of temporal lobe epilepsy. J Neurosci 23:8471-8479.

Lee H, Chen CX, Liu YJ, Aizenman E, Kandler K (2005) KCC2 expression in immature rat cortical neurons is sufficient to switch the polarity of GABA responses. Eur J Neurosci 21:2593-2599.

Lothman EW, Stringer JL, Bertram EH (1992) The dentate gyrus as a control point for seizures in the hippocampus and beyond. Epilepsy Res Supp 7:301-313.

Martina M, Royer S, Pare D (2001) (2001) Cell-type-specific GABA responses and chloride homeostasis in the cortex and amygdala. J Neurophysiol 86:2887-2895.

Marty S, Wehrle R, Alvarez-Leefmans FJ, Gasnier B, Sotelo C (2002) Postnatal maturation of $\mathrm{Na}^{+}, \mathrm{K}^{+}, 2 \mathrm{Cl}^{-}$cotransporter expression and inhibitory synaptogenesis in the rat hippocampus: an immunocytochemical analysis. Eur J Neurosci 15:233-245.

Mello LE, Cavalheiro EA, Tan AM, Kupfer WR, Pretorius JK, Babb TL, Finch DM (1993) Circuit mechanisms of seizures in the pilocarpine model of chronic epilepsy: cell loss and mossy fiber sprouting. Epilepsia 34:985-995.

Nabekura J, Ueno T, Okabe A, Furuta A, Iwaki T, Shimizu-Okabe C, Fukuda A, Akaike N (2002) Reduction of KCC2 expression and $\mathrm{GABA}_{\mathrm{A}}$ receptor-mediated excitation after in vivo axonal injury. J Neurosci 22:4412-4417.

Overstreet-Wadiche L, Bromberg DA, Bensen AL, Westbrook GL (2005) GABAergic signaling to newborn neurons in dentate gyrus. J Neurophysiol 94:4528-4532. 
Owens DF, Boyce LH, Davis MB, Kriegstein AR (1996) Excitatory GABA responses in embryonic and neonatal cortical slices demonstrated by gramicidin perforated-patch recordings and calcium imaging. J Neurosci 16:6414-6423.

Parent JM, Yu TW, Leibowitz RT, Geschwind DH, Sloviter RS, Lowenstein DH (1997) Dentate granule cell neurogenesis is increased by seizures and contributes to aberrant network reorganization in the adult rat hippocampus. J Neurosci 17:3727-3738.

Payne JA, Stevenson TJ, Donaldson LF (1996) Molecular characterization of a putative $\mathrm{K}-\mathrm{Cl}$ cotransporter in rat brain. A neuronal-specific isoform. J Biol Chem 271:16245-16252.

Plotkin MD, Snyder EY, Hebert SC, Delpire E (1997) Expression of the $\mathrm{Na}-\mathrm{K}-2 \mathrm{Cl}$ cotransporter is developmentally regulated in postnatal rat brains: a possible mechanism underlying GABA's excitatory role in immature brain. J Neurobiol 33:781-795.

Rafiq A, DeLorenzo RJ, Coulter DA (1993) Generation and propagation of epileptiform discharges in a combined entorhinal cortex/hippocampal slice. J Neurophysiol 70:1962-1974.

Rivera C, Voipio J, Payne JA, Ruusuvuori E, Lahtinen H, Lamsa K, Pirvola U, Saarma M, Kaila K (1999) The $\mathrm{K}^{+} / \mathrm{Cl}^{-}$co-transporter KCC2 renders GABA hyperpolarizing during neuronal maturation. Nature 397:251-255.

Rivera C, Li H, Thomas-Crusells J, Lahtinen H, Viitanen T, Nanobashvili A, Kokaia Z, Airaksinen MS, Voipio J, Kaila K, Saarma M (2002) BDNFinduced $\operatorname{TrkB}$ activation down-regulates the $\mathrm{K}^{+}{ }_{-} \mathrm{Cl}^{-}$cotransporter KCC2 and impairs neuronal $\mathrm{Cl}^{-}$extrusion. J Cell Biol 159:747-752.

Rivera C, Voipio J, Thomas-Crusells J, Li H, Emri Z, Sipila S, Payne JA, Minichiello L, Saarma M, Kaila K (2004) Mechanism of activity- dependent downregulation of the neuron-specific $\mathrm{K}-\mathrm{Cl}$ cotransporter KCC2. J Neurosci 24:4683-4691.

Salazar AM, Jabbari B, Vance SC, Grafman J, Amin D, Dillon JD (1985) Epilepsy after penetrating head injury. I. Clinical correlates: a report of the Vietnam Head Injury Study. Neurology 35:1406-1414.

Schmidt-Hieber C, Jonas P, Bischofberger J (2004) Enhanced synaptic plasticity in newly generated granule cells of the adult hippocampus. Nature 429:184-187.

Toyoda H, Ohno K, Yamada J, Ikeda M, Okabe A, Sato K, Hashimoto K, Fukuda A (2003) Induction of NMDA and $\mathrm{GABA}_{\mathrm{A}}$ receptor-mediated $\mathrm{Ca}^{2+}$ oscillations with KCC2 mRNA downregulation in injured facial motoneurons. J Neurophysiol 89:1353-1362.

van den Pol AN, Obrietan K, Chen G (1996) Excitatory actions of GABA after neuronal trauma. J Neurosci 16:4283-4292.

Wake H, Watanabe M, Moorhouse AH, Kanematsu T, Horibe S, Matsukawa N, Asai K, Ojika K, Hirata M, Nabekura J (2007) Early changes in KCC2 phosphorylation in response to neuronal stress result in functional downregulation. J Neurosci 27:1642-1650.

Weiss GH, Salazar AM, Vance SC, Grafman JH, Jabbari B (1986) Predicting posttraumatic epilepsy in penetrating head injury. Arch Neurol 43:771-773.

Yamada J, Okabe A, Toyoda H, Kilb W, Luhmann HJ, Fukuda A (2004) $\mathrm{Cl}^{-}$ uptake promoting depolarizing GABA actions in immature rat neocortical neurones is mediated by NKCC1. J Physiol (Lond) 557:829-841.

Zhu L, Lovinger D, Delpire E (2005) Cortical neurons lacking KCC2 expression show impaired regulation of intracellular chloride. J Neurophysiol 93:1557-1568. 